\title{
La cocina como espacio transicional nutritivo frente a un sistema de apego deficitario. "Un Inicio para todos"1
}

\author{
Ignacio Blasco Barrientos ${ }^{2}$ \\ Colaboradores: Gloria de Rubio, Rocio Orellana, Edu Roselló
}

\begin{abstract}
El trabajo ofrece una visión global del proyecto social "Un Inicio Para Todos" como espacio de reinserción social para jóvenes en riesgo de vulnerabilidad mediante la formación en cocina y catering. Proyecto basado en ofrecer a los jóvenes que acuden a nuestro recurso, espacios y profesionales que actúen como objetos transicionales para reinstaurar un sistema de apego deficitario a la vez que se les forma como futuros profesionales dentro del sector alimentario. Revisaremos superficialmente la preocupante situación psicosocial de la población antes descrita para poder entender, posteriormente, desde la teoría del apego y el psicoanálisis relacional, la intervención y trabajo que realizamos con los chicos y chicas que se forman con nosotros/as.
\end{abstract}

Palabras clave: Rehabilitación Psico-social, Cocina, Psicoterapia, Apego deficitario.

This paper offers a global visión of the social Project "Un Inicio para todos" as a space for social reintegration for Young people at risk of vulnerability through cooking and catering training. Project based on offering young people who come to our resource, spaces and professionals to act as a transitional objects to restore a déficit attachment system while being trained as future professionals in the hostelry sector. We will superficially review the worrying psychosocial situation of the population described above to be able to understand, subsequently, from the theory of attachment and relational psychoanalysis, the intervention and work we do with the Young boys and girls who are trained with us.

Key Words: Psycho-social rehabilitation, Cooking, Psychotherapy, Deficit attachment. English Title: The hostelry as a nutritional transitional space versus a déficit attachment system. "Un Inicio para todos" (A start for everyone)

\section{Cita bibliográfica / Reference citation:}

Blasco, I. con la col. de G. de Rubio, R. Orellana, E. Rosales (2020). La cocina como espacio transicional nutritivo frente a un sistema de apego deficitario. "Un Inicio para todos". Clínica e Investigación Relacional, 14 (1): 91-102. [ISSN 1988-2939] [Recuperado de www.ceir.info ] DOI: 10.21110/19882939.2020.1401

\footnotetext{
${ }^{1}$ Una primera versión de este trabajo fue presentada en la VIIIa reunión bienal de IARPP-España, celebrada en Sevilla, Octubre de 2019.

2 Psicólogo G. Sanitario y Psicoterapeuta. Miembro de Ágora Relacional y del Instituto de Psicoterapia Relacional, Madrid.
} 


\section{UN INICIO: Bases y proyecto.}

Un Inicio Para Todos, desde ahora UIPT, es fundado por Gloria De Rubio y Edu Roselló, dos profesores que, hace diez años, ven cómo uno de sus alumnos, fruto de una situación extrema, comete un error, un delito por el que es privado de libertad y conlleva su entrada en un centro de menores. En un intento de acompañar y sostener las dificultades de la nueva situación del alumno, las cuales se sumaban a las ya de por si espinosas condiciones vitales previas a entrar al centro, los profesores deciden acudir puntualmente a visitarle; es allí donde detectan las dificultades que ofrece el sistema de menores infractores para poder elaborar o entender por parte del menor, la situación en la que se encuentra y de la que es responsable, no sólo eso, detectan la evidente dificultad de que ese alumno pueda salir del laberinto psicosocial en el que ha sido incluido, o dicho de otra forma, detectan que, el camino de la exclusión, sólo tiene billete de ida.

Desde ese mismo momento, Gloria y Edu, comenzarán a pensar y estructurar actividades (al principio deportivas, después culinarias) para ayudar a estos jóvenes, comenzaron a crear, sin saberlo, lo que hoy es UIPT.

Diez años después, UIPT es una empresa social dentro de la industria alimentaria, que tiene como misión formar, mediante su asociación homónima, a jóvenes en riesgo de exclusión social. Nace con el objetivo de ser independiente y sostenible económicamente, permitiendo esto, una libertad absoluta en las decisiones dentro del proyecto social. Para ello, se crea una cocina industrial que desarrolla, produce y vende productos de $4^{\circ}, 5^{\mathrm{a}}$ gama, así como un servicio de catering que hoy ofrece más de nueve servicios semanales. Una estructura empresarial altamente cuidada que permite sustentar el programa de formación que ha dado cabida a cerca de 200 jóvenes en los últimos tres años.

Desde una perspectiva global y multidisciplinar desarrollada por profesionales de la hostelería, educación, filosofía y psicología, se ofrece a estos/as jóvenes un espacio novedoso, humano y didáctico donde poder desarrollar competencias laborales y donde poder verse desde una perspectiva nueva o, en el mejor de los casos, encontrar su valía, con todo lo que esto implica.

\section{Perspectiva psicosocial: "Los jóvenes (NO) son el futuro"}

Los índices de crecimiento de personas en riesgo de vulnerabilidad son alarmantes, en el año 2018, cerca de 12 millones de personas se encontraban en riesgo de pobreza o exclusión social, esto es un $26,1 \%$ de la población española (Informe AROPE 2019); más alarmante aún es englobar a todas esas personas bajo esa nomenclatura: "riesgo de vulnerabilidad social", nomenclatura que facilita definir un sector específico pero, a su vez, excluye la particularidad 
del individuo que hay detrás: Inmigración, pobreza, enfermedad mental, personas sin hogar o trata de personas son algunos de los subgrupos que coexisten bajo esa vulnerabilidad, cada uno/a con sus particularidades, subjetividades y tramas relacionales, todos/as ellos/as con un potencial, muchas veces invalidado o negado.

Si acotamos el campo a nivel sociodemográfico, la población menor de 18 años, podemos ver un aumento del porcentaje de riesgo de pobreza hasta el 26,8 \% de la población en España, donde un $6,5 \%$ soporta privación material severa, el $7,7 \%$ lo hace en pobreza severa y el $7,7 \%$ vive en hogares con baja intensidad de empleo (AROPE 2019). La tendencia en los últimos años no arroja datos que alivien esta situación, por el contrario, parece que, lejos de reducirse los porcentajes de exclusión social en menores, aumentan o, en el mejor de los casos, quedan estáticos.

La institucionalización de las personas vulnerables en general y los jóvenes en particular es una realidad; se cosifican y generalizan elementos que obvian la las particularidades, la especificidad de cada individuo, llevándonos esto a una solución parcial de las necesidades de esta población, una solución temporal que no ofrece las garantías de reinserción o desarrollo esperables.

El asistencialismo, en el que tan fácil es caer, es otro elemento que, suponiendo una gran ayuda para ciertas personas, alimenta la verticalidad social frenando cualquier posibilidad de dotar o habilitar a las personas vulnerables de herramientas para poder ser agentes de su propio cambio.

Por último, vemos necesario señalar el flaco favor que hacen los discursos populistas y extremistas, así como la falta delicadeza de muchos medios informativos ante temas como, por ejemplo, los MENAS. Discursos que nos permitimos englobar dentro de una instaurada y creciente aporofobia, concepto desarrollado por Adela Cortina en los años 9o. Aporofobia como miedo, rechazo u odio al pobre, que surge como una construcción social que relaciona a las personas pobres con delincuencia, situándonos en el imaginario social como posibles delincuentes, antes que como potenciales víctimas de discriminación y/o violencia.

\section{¿Quiénes son estos/as jóvenes? Lo que la exclusión esconde.}

Como hemos mencionado antes, la terminología, implícita e involuntariamente, reduce el significado e implicaciones subyacentes de lo que representa. Ante esto queremos ofrecer una visión de las personas, de los y las jóvenes con los que trabajamos, convivimos, disfrutamos y sufrimos; una visión que se quedará corta en comparación con el valor que individualmente, cada uno de ellos y ellas, tiene. 
Nos nutrimos de diversos agentes sociales: ASPAS, Servicios sociales, programas de reinserción social de jóvenes en libertad vigilada, asociaciones de reinserción de víctimas de la trata de personas, así como particulares. Todas ellas nos derivan jóvenes de entre 16 y 26 años que han quedado excluidos, fuera de los círculos sociales, familiares, académicos y/o laborales.

La formación está estructurada en cursos de ayudante de cocina y catering, es una formación completamente gratuita, por lo que somos un recurso cada vez más valorado por las entidades con las que colaboramos. Estas nos derivan jóvenes que están interesados/as en la cocina y se sienten capaces de comenzar algo nuevo, la mayoría de ellos han tomado conciencia parcial de su situación y sienten la necesidad de comenzar algo que les enganche y les permita independizarse, en todos los sentidos posibles.

Realizamos una entrevista individual una vez realizada la derivación por parte de la entidad, no sólo entrevistamos al potencial alumno/a, incluimos en la medida de lo posible a la entidad o, en casos puntuales, a terceros (familiares, en su mayoría). En esta entrevista, el único requisito es el querer "estar", evaluamos esto como la necesidad de avanzar, de crecer, de desarrollarse, una posición activa, un atreverse a hacer algo nuevo, a ocupar espacios diferentes. Nos encantaría poder coger toda la demanda que tenemos, pero, por motivos evidentes de espacio y calidad formativa, sólo podemos coger alrededor de 20-25 por periodo formativo. Una vez seleccionados, se realiza una entrevista más incisiva para conocer la realidad del chico o chica: situación psicosocial, necesidades, vínculos fundantes y actuales, familia, posibles consumos, enfermedades, aficiones, motivaciones.

En esta entrevista, tenemos acceso a una información muy valiosa: El contacto interpersonal que ofrece el alumno/a.

También encontramos espontaneidad, humor y ganas en ese primer encuentro, siempre rescatamos en mayor o menor medida signos de una autenticidad esperanzadora.

\section{Teoría del apego, micro trauma y psicoanálisis relacional.}

¿Qué encontramos? Encontramos a jóvenes profundamente dañados social y psíquicamente; altos niveles de disociación, función reflexiva llamativamente empobrecida, así como una acumulación de microtraumas afianzados en los diversos átomos sociales en los que han vivido. Todo ello nos lleva a jóvenes con sistemas de apego predominantemente evitativos y ambivalentes, así como un self severamente empobrecido, entendiendo self como un centro de iniciativa y receptor de impresiones (H. Kohut).

Con las particularidades de cada historia personal, podemos establecer las profundas disfunciones de la parentalidad que se han dado en la vida de estos chicos y chicas. La teoría 
del apego propone un marco sistemático para relacionar la interacción disfuncional temprana progenitor/a-Hijo/a con el desarrollo del niño a través de una senda sub-óptima con sus secuelas psicopatológicas (Perris, 1994).

Dentro de estas disfuncionalidades, destacamos las comunicaciones patogénicas que los jóvenes han recibido por parte de sus vínculos fundantes de forma reiterada y constante, aumentando así sus consecuencias negativas.

La invalidación de la petición infantil de apoyo y comprensión por parte de los progenitores, la negación de la percepción del niño de ciertos eventos o hitos familiares, la invalidación de la experiencia subjetiva, las comunicaciones culpógenas o el doble vínculo son algunas de las experiencias que rescatamos en la trama relacional de los jóvenes que se forman en UIPT.

Sumamos a lo anterior la falta de consistencia y estabilidad física-psíquica que provocan las situaciones psicosociales en las que se desarrolla el niño o niñas: padres biológicos que no están, no ejercen, o directamente dejan el cuidado de sus hijos a terceros; múltiples cuidadores que no permiten una referencia clara y segura; rupturas traumáticas, en ocasiones con mucha violencia intrafamiliar perpetrada por los progenitores; madres o padres que, al quedarse con la custodia del niño/a, les exponen a la inconsistencia fruto de la presencia de múltiples parejas dentro del hogar. Todo ello nos acerca al concepto de trauma acumulativo o micro-trauma: Tensión crónica y acumulativa que interrumpe el desarrollo sano (M. Khan); Una versión micro del trauma, menos intensa, menos obvia o directa en su cualidad destructiva y, por lo tanto, de forma más plausible de ser negada por uno mismo o por el otro. La cualidad hiriente podría residir solo en el tono subyacente o en las implicaciones periféricas del acto, más que en su mensaje principal (M. Crastnopol).

Ante este escenario UIPT surge como un espacio formativo y re-instaurativo, pero no podemos perder de vista la enorme responsabilidad que conlleva acompañar a estos chicos y chicas, sobre todo por la visión que tenemos de ellos/as y la ambición del proyecto, aspectos que nos permiten diferenciarnos de otras ofertas formativas.

La cocina como medio, no como fin, medio para la reinserción, para la toma de conciencia, para pararse; los espacios y profesionales que ofrecemos como elementos sostenedores, capaces de devolver una imagen de sí mismos restauradora, clara y constante; fomentar experiencias nuevas de relación con objetos y personas con el único fin de explorar(se) de forma distinta. En definitiva, una suma de vivencias relacionales y transicionales para llegar a una potente experiencia emocional correctiva (F. Alexander) 


\section{¿Por qué la cocina? Implicaciones explícitas e implícitas.}

La cocina como oficio, representa uno de los sectores más independientes de la trayectoria curricular como filtro para la contratación, por ello, entendemos que es un sector que puede dar cabida y facilitar la inserción laboral, así como el posterior desarrollo de estos/as jóvenes. La cocina, sus ritmos, sensaciones, procesos y mecánica como medio para sostener y facilitar el contacto con su subjetividad. El trabajo en equipo, la producción en cadena, la interdependencia de puestos de trabajo, la atención requerida por la tarea y la interacción con el producto como elementos facilitadores de una visión de sí mismos distinta y con proyección de futuro.

La cocina implica esfuerzo, constancia, observación, curiosidad, compañerismo y análisis; La cocina es mucho más que la simple elaboración de alimentos, es un espacio en el que si no hay organización, todo se desvanece.

"En asuntos humanos, lo más complejo, sólo puede desarrollarse a partir de lo más simple" (D.W. Winnicott)

Estos chicos y chicas han vivido en el error constante, desde sus primeros años de vida los ha acompañado el caos, el castigo indiscriminado y la consiguiente desestabilización psíquica fruto del propio sistema de apego de sus vínculos fundantes o debido a la condición de tutela de las instituciones que nos derivan; y por otra parte encontramos la desestabilización física, establecida por los procesos migratorios, los constantes cambios de país, ciudad o domicilio, en ciertas ocasiones vivir en la calle por largas temporadas. Por ello, en UIPT el error es una oportunidad, el error tiene un devenir positivo dentro de la nave, el error como punto de partida. En nuestra cocina de producción, tenemos el tiempo, el espacio y el personal necesario para convertir un error en una oportunidad de aprendizaje y desarrollo, no sólo en el corte de una zanahoria, sino en las relaciones que se establecen en la nave, entre ellos y con nosotros. También en los potenciales conflictos y en la respuesta ante los diversos mecanismos actuadores que pongan en marcha.

Poder formar a los jóvenes en este sector, sólo es posible en una cocina de producción, previamente se intentó en un restaurante, pero, la tensión del servicio, la inmediatez de los procesos y la presión del cliente final tan cerca eran contraproducentes, ya que podían darse situaciones re traumatizantes que reactivasen las sensaciones de futilidad, incapacidad o rechazo que tan familiares son para estos chicos y chicas.

Por el contrario, el trabajo en una cocina de producción, supervisado por un equipo profesional, permite una libertad guiada única, una libertad guiada sostenida por una base segura y comprensiva. 
"En la niñez y la adolescencia, una característica de la respuesta sensible es la capacidad parental de ver al niño como un ser humano con su propia individualidad y sus propias necesidades como separadas con respecto a las de los demás. Esto implica ofrecerle una base segura y al mismo tiempo permitirle el desarrollo de conductas exploratorias. Una libertad guiada." (M. Marrone)

\section{El Servicio de catering: Un paso intermedio. Implicaciones.}

Además, el servicio de catering ofrece la posibilidad de ver, desde el origen, cómo se gestiona un evento. La preparación de los platos y el menaje, la orden de catering, el trabajar en espacios pequeños y lo más importante, el salto al vacío que les produce dar un servicio: La tensión previa, organización para que todo esté listo, cuidar el detalle, la imagen personal, la exposición ante múltiples ojos, servir y explicar lo elaborado por uno/a mismo/a, el contacto con el cliente. El servicio de catering les habilita como profesionales, pero, si miramos más allá, les posibilita la interacción con múltiples personas donde ellos tienen un protagonismo absoluto: Imagen, diálogo, lenguaje no verbal o equilibrio, son sólo algunos aspectos que desarrollan en estos espacios. No sólo eso, son partícipes de un proceso largo y minucioso donde su lugar, en muchas ocasiones, es imprescindible, no tenemos ninguna duda que subjetivamente, esta experiencia es altamente beneficiosa para ellos y ellas.

Entendemos la cocina como un vehículo, nunca como un fin. Por este motivo pensamos en un trabajo integral con el joven: Un trabajo humano que nos permita conocer la idiosincrasia del joven y ofrecerle un crisol de espacios de potencial desarrollo con el fin de motivarle hacia un proyecto vital propio. Nuestra intención es poder formar a jóvenes para que sean libres y críticos en sus decisiones, algo que pocas veces han experienciado.

\section{Espacios transicionales: La nave y el equipo}

La nave está diseñada y decorada de tal forma que los espacios sean amplios, bellos y facilitadores. Además de las instalaciones de cocina contamos con 600 metros cuadrados donde encontramos salas de formación, un comedor amplio, donde compartimos la comida de personal todos y todas juntos, así como una oficina abierta pegada a las instalaciones de cocina para favorecer el contacto y la horizontalidad entre los jóvenes y adultos.

Utilizamos la palabra "adulto" para referirnos a todo el personal profesional que convive, acompaña y está con los jóvenes en formación. 
Así como los espacios son estructuras pensadas para favorecer desarrollo potencial del joven, todo adulto mediante la relación que establece con los jóvenes, les ofrece una serie de posibilidades que van desde aspectos puramente técnicos hasta encuentros sensibles o, en el mejor de los casos, puede darse esto de forma simultánea.

"Los efectos psicológicos del trauma son más severos si el trauma es generado por el ser humano, perpetrado por una figura de apego, con crueldad, repetido en la infancia. Cuanto más vulnerable sea la víctima, mayor será el efecto del trauma." (La teoría del apego, un enfoque actual. Mario Marrone)

Todo el personal de UIPT es un potencial vínculo de desarrollo para los jóvenes, todos y todas participamos en su proceso formativo en mayor o menor medida, los chicos y chicas realizan tareas con cada uno de los que allí trabajamos. La limpieza de la nave, la colada de cocina y catering, el transporte o el orden de los almacenes forma parte su formación. Todos los jóvenes, mediante un sistema de rotación, pasan por los diferentes puestos que conllevan el mantenimiento de la nave y cocina (Cuarto frio, cuarto caliente, envasado, recepción, limpieza y office).

En la nave, existe un equipo profesional, coordinado por el jefe de cocina; en oficina encontramos personal de contabilidad, comunicación, marketing, comercial, diseño y/o calidad. UIPT nace para y por la formación de jóvenes, por ello todo el personal está directamente implicado en los procesos formativos, de acompañamiento y mentoría que ofrecemos. Uno de los elementos diferenciales a otras empresas del sector es que todos y cada uno de los trabajadores estamos presentes en las tareas de cocina. El motivo principal es ese "estar" con los chicos y chicas que formamos, acompañarlos de forma implicada, favorecer identificaciones positivas en ellos que les permitan volcarse en su proceso de aprendizaje. Mas allá de las competencias laborales o de cocina, en UIPT miramos de reojo a las comunidades terapéuticas surgidas en Inglaterra en el siglo XIX, rescatando la horizontalidad física y relacional que allí favorecían, de tal forma que todos/as acompañamos a los jóvenes en las diversas tareas que la nave requiere, cuidando a los espacios, nos cuidamos a nosotros/as, permitimos paulatinamente y dependiendo del caso que estén presentes en situaciones y tareas diversas (reuniones, elaboración de presupuestos, contabilidad, visita a clientes, entrega de pedidos, contratar caterings).

Todas estas relaciones se dan mediante un protocolo y bajo supervisión del equipo de formación, compuesto por profesionales de la educación, filosofía trabajo social y psicología. Desde formación hemos diseñado de forma paulatina (y con bastantes dificultades) una serie de protocolos de convivencia e interacción que aseguren relaciones estables, coherentes, saludables y, que, por encima de todo, prime el bienestar y proceso formativo del joven. 
Por ello, entendemos que todo proceso de re-estructuración ha de ser mediante figuras significativas capaces de habilitar un sistema de apego más adaptativo, una elaboración de la realidad psíquica que favorezca nuevos espacios de relación más profundos y estables, con ellos mismos y con su entorno.

La formación es un vehículo que permite la reparación parcial de los objetos internos dañados mediante una amplia, respetuosa y paciente comprensión de la situación vital y social del joven. El grupo (compañeros, adultos e institución) como sostén ante una segunda oportunidad en la vida. El grupo como espacio transicional entre dos ciclos vitales.

\section{Hasta la cocina y más allá: Competencias transversales y pluriversidad.}

Más allá de la visión "novedosa" o "diferencial" que presentamos en la formación técnica o de competencias laborales, el elemento diferencial más potente que ofrecemos es lo que denominamos "pluriversidad: Un lugar único para desarrollar competencias transversales: para conocerse y relacionarse de una forma novedosa, alejada de dispositivos electrónicos o de las interacciones líquidas con las personas y objetos, tan en boga hoy día. Una formación plural y diversa, transversal y sensible. Espacios de relación que permitan a los jóvenes entrar en contacto y aprender de una forma novedosa, espontánea y creativa todo aquello que rechazaron, negaron u obviaron en su proceso de formación reglada.

La pluriversidad, espacio encuadrado en dos horas diarias por la tarde, comprende dinámicas donde se ofrece a los jóvenes material audiovisual, dinámicas grupales, lectura, manualidades, deporte, visitas culturales y/o visitas de colaboradores del proyecto. Estos espacios tienen la misma importancia que el tiempo en cocina para su formación.

Transversales: el grupo como mecanismo exploratorio y protector: Cada quince días, la mitad del grupo no entra en cocina para, mediante dinámicas grupales como el juego, la dramatización o el diálogo, trabajar aspectos más personales, así como favorecer el bienestar y respeto grupal, ya que los cursos tienen una duración de cuatro meses donde, la convivencia, puede originar situaciones complicadas, este grupo, indirectamente sirve como prevención.

Se plantea un trabajo psicoeducativo que permite a los jóvenes pensar en contacto con los demás, tomar conciencia de lo que son y por qué lo son, con el objetivo de ofrecerles la posibilidad de cambiar su devenir como personas, que sean ellos/as quienes elijan dentro de una perspectiva coherente con su sistema vital. Que tengan una visión global que les habilite para no sólo pensarse desde el fracaso o el trauma, sino que se sientan en posiciones capacitantes para la sociedad y para sí mismos. 
En ocasiones vemos como entran en contacto con emociones intensas, otras veces nos abandonan, otras nos atacan, muchas veces vemos, como, por fin, encuentran un espacio donde estar cómodos, sorprendentemente no saben cómo actuar en estos casos, entendemos que están ante algo nuevo, distinto. Ese es el objetivo de la formación.

\section{Pabellones externos: Prácticas.}

No todo se termina en la nave, de nada serviría el proceso formativo que llevamos a cabo con los jóvenes si no facilitásemos una continuidad fuera de ella.

Una vez terminado el proceso formativo, que dura unos 4 meses, entendemos que los jóvenes, están capacitados para ir a un restaurante de prácticas, ya sea en sala (por la experiencia en los catering) o como ayudante de cocina.

Gracias a la trayectoria de UIPT, los contactos establecidos y la idiosincrasia del negocio de la hostelería en España contamos con más de treinta restaurantes / empresas hosteleras colaboradoras que funcionan como pabellón externo, de tal forma que acogen a nuestros alumnos/as facilitándoles unas prácticas reales en su establecimiento y, en el mejor de los casos, facilitando su contratación. Hay que aclarar que no todos los alumnos/as optan a las prácticas, para ello han de cumplir una serie de criterios básicos para poder acceder a ellas.

Los consideramos pabellones externos ya que son parte de la formación, los responsables de los diferentes restaurantes que nos facilitan el espacio para los chicos/as, han de comprometerse con el proyecto para ser un espacio o vínculo sanador más dentro del proceso del joven. Somos muy insistentes en el concepto de colaboración que queremos con estos restaurantes para no caer en el asistencialismo, nadie hace un favor a nadie, ambas instituciones trabajamos conjuntamente por y para el joven. Esto implica tomarse el tiempo necesario para conocer aspectos importantes del chico o chica que les enviamos, así como a venir a la nave a dar una clase magistral o compartir espacios (pluriversidad) con los jóvenes, que, en ese momento, tengamos en formación.

\section{La importancia del trabajo en red.}

Hemos de poner en valor el trabajo comunitario frente a la desigualdad y traumas sociales, los vínculos que UIPT ha creado fuera de la nave nos han permitido conocer un tejido asociativo potente que, inevitablemente, está cada vez más desgastado por la falta de recursos: entidades sociales con equipos capaces de hacer frente a situaciones de vulnerabilidad social graves, profesionales dispuestos a una colaboración abierta y constante en relación a los jóvenes que 
nos derivan, así como auténticas muestras de creatividad para hacer frente a esos escasos medios que tienen.

Esto nos invita a pensar que el verdadero impacto social, impacto que implique un cambio real, sólo puede darse mediante el trabajo en red, fruto de la coordinación múltiple entre profesionales y entidades; un tejido asociativo fuerte, capaz de responder, en este caso a las necesidades y déficits de los jóvenes y su entorno, hasta que adquieran una mínima independencia no sólo laboral, sino psicosocial.

No debemos pasar por alto que lo que permite que este tejido asociativo funcione coordinado, es el alto desgaste de los y las profesionales que lo forman, una implicación que, excede de lejos, lo que sus contratos dictan. Por tanto, muchas veces, la eficacia o eficiencia del recurso, tiene un tiempo limitado, el de la salud de los profesionales que lo conforman.

\section{Conclusiones}

UIPT nace como proyecto social que permita a jóvenes en riesgo de exclusión desarrollarse laboral y humanamente; sorprendente y gratamente, los profesionales que allí trabajamos también estamos en constante crecimiento profesional y humano. La exigencia diaria en UIPT consisten en optimizar mediante un reajuste progresivo los múltiples aspectos y detalles que implica el proyecto: parte empresarial, formativa y la cohesión de ambas. Esto permite poder plasmar nuestra experiencia en trabajos como el presente, animándonos a escribir y contar más lo que es UIPT.

Concluimos, por tanto, la necesidad de comunicarse como equipo, la importancia de pensar cada situación, de escribir las experiencias y de buscar espacios que favorezcan esto. Estar en contacto con estos perfiles tiene muchas implicaciones y responsabilidades, para hacerlas frente, el equipo ha de protegerse y cuidarse.

Como todo proyecto, surge como respuesta a una demanda social en un momento histórico determinado, los datos e información ofrecidos en el apartado psicosocial del trabajo, nos hacen pensar y concluir en la importancia del trabajo comunitario y en red, lo grupal como herramienta sanadora y protectora de la sociedad. En definitiva, poner en valor la red social originaria.

Por último, concluir la importancia que la teoría tiene para sostener el trabajo en UIPT. La experiencia nos permite afirmar que favorecer espacios de transición bajo el manto de una mirada esperanzadora y nueva permite otorgar experiencias emocionales correctivas suficientemente potentes como para reestructurar los sistemas de apego que los jóvenes traen 
consigo. Todos los textos y teorías estructuran el proyecto formativo y a los profesionales que trabajamos en él, permitiéndonos una mayor seguridad técnica.

Para finalizar, nos gustaría hacer una mención especial al equipo que hace posible la lectura de este texto. Leticia Rodríguez, Rafa Cordón, Marta Lobato, Michael Sinda, Moussa Shannon, Rubén Gálvez, Paco Polo, Malú y David. Sin su entrega, disposición, energía y escucha, sería muy difícil.

Y, lo más importante, agradecer a todos esos chicos y chicas que nos dan lecciones de vida cada día, que nos permiten acceder a ellos, que nos ayudan, acompañan y sostienen, el futuro es vuestro.

\section{REFERENCIAS}

Abello Blanco, Augusto y Liberman Isod, Ariel (2011). Una Introducción a la obra de D.W.Winnicott. Contribuciones al pensamiento relacional. Madrid. Ágora relacional, número 3.

Alexander, F. y French, T. (1965). Terapéutica psicoanalítica. Capítulo IV: El Principio de la experiencia emocional correctiva. Biblioteca del hombre contemporáneo.

Avila Espada, Alejandro (2013). La Tradición interpersonal. Perspectiva social y cultural en psicoanálisis. Madrid. Colección pensamiento relacional, número 8.

Crastnopol, Margaret (2015). Micro-Trauma. Una concepción psicoanalítica del daño psíquico acumulativo. Madrid. Colección pensamiento relacional, número 21.

García España, Elisa (2014). Delincuencia de inmigrantes y motivaciones delictivas. InDret 4/2014 Revista para el análisis del derecho. Barcelona

Marrone, Mario (2004). La teoría del apego. Un enfoque actual. Madrid. Psimática.

Winnicott, Donald (1991). Deprivación y delincuencia. Buenos Aires, Paidos.

$9^{\circ}$ Informe AROPE (2019). El estado de la pobreza. Seguimiento del indicador de pobreza y exclusión social en España 2008 a 2018. EAPN-ES

Original recibido con fecha: 2/12/2019 Revisado: 30/12/2019 Aceptado: 15/03/2020 